\title{
Regression of a large gastric MALT lymphoma with antibiotic treatment to eradicate Helicobacter pylori
}

\author{
J Martin, S Boyle, M Jacyna
}

\begin{abstract}
Summary
We report a case of a large low-grade gastric lymphoma of mucosa-associated lymphoid tissue (MALT), which regressed following the eradication of concurrent Helicobacter pylori infection. This case lends further support to a policy of $H$ pylori eradication as a first line therapy for all these lesions, irrespective of size. The long-term prognosis of tumours treated in this way, however, needs further evaluation.
\end{abstract}

Keywords: Helicobacter pylori, MALT tumour

There is increasing evidence that Helicobacter pylori is causally linked to some types of gastric lymphoma and many reports have suggested that eradicating the organism may result in regression of some low-grade tumours. ${ }^{1} \mathrm{We}$ report the successful treatment of a large gastric low grade mucosa-associated lymphoid tissue (MALT) lymphoma with antibiotics to eradicate $H$ pylori. This result supports previous evidence that even large tumours may be responsive to $H$ pylori eradication therapy.

\section{Case report}

A 57-year-old man was referred for investigation of a two-month history of burning epigastric pain. He also described one episode of malaena, but no haematemesis. There was no previous history of dyspeptic symptoms, no weight loss, and he was not currently taking nonsteroidal anti-inflammatory drugs.

Examination was normal; he was not clinically anaemic, and there was no lymphadenopathy or hepatosplenomegaly. Routine biochemistry, liver function and full blood count were normal. An oesophago-gastroduodenoscopy revealed a large ulcer on the inscisura with shouldering and rolled edges, highly suggestive of carcinoma (figure 1). Biopsies of the ulcer showed a population of lymphoid cells infiltrating, and destroying, the crypt epithelium. $H$ pylori were seen in the specimen (figure 2). A diagnosis of MALT lymphoma was made and the patient was commenced on $H$ pylori eradication therapy consisting of omeprazole $20 \mathrm{mg}$ bid, amoxicillin $750 \mathrm{mg}$ bid, and metronidazole $400 \mathrm{mg}$ tid. Computed tomography of the abdomen, bone marrow aspirate and trephine were normal.

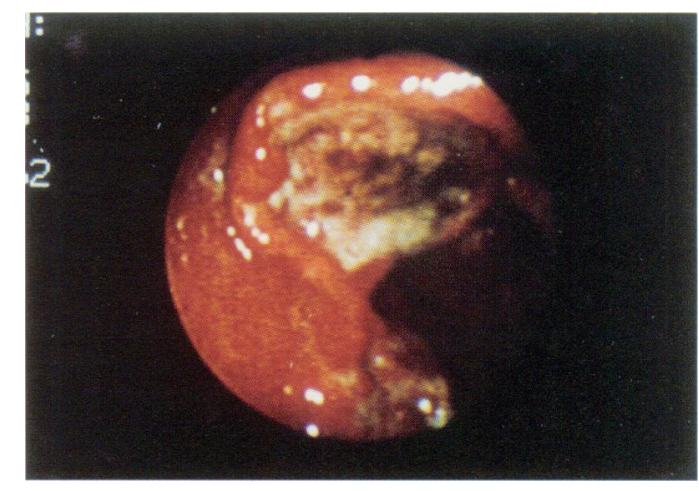

Figure 1 Initial endoscopic appearance of malignant ulcer on inscisura

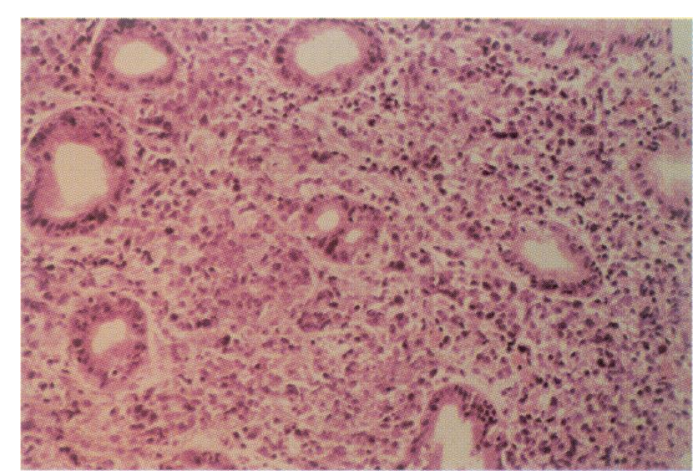

Figure 2 A mucosal infiltrate of lymphoid cells with destruction of gland epithelium

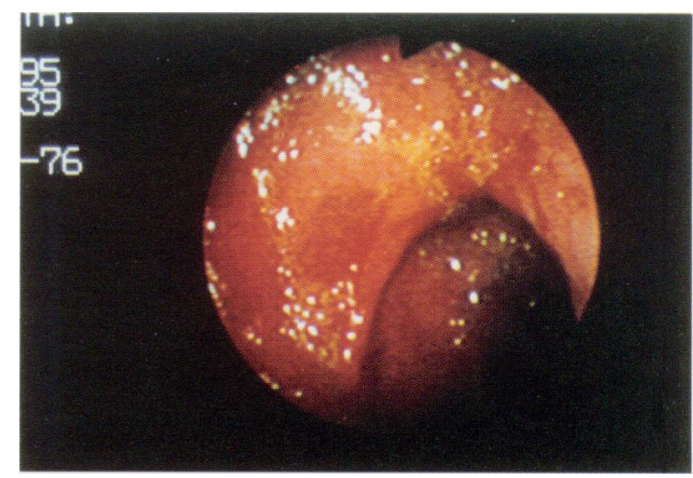

Figure 3 Endoscopic appearance of same area after four weeks treatment 
Four weeks later the patient was re-endoscoped and only a small superficial ulcer remained, with surrounding gastritis (figure 3). Histology demonstrated only small areas of residual lymphoma and no $H$ pylori. The patient was treated with a further month of omeprazole $20 \mathrm{mg}$ bid and amoxicillin $1 \mathrm{~g}$ bid. A further endoscopy following this treatment revealed only a small scar. Multiple biopsies of the area, as well as histological mapping of the stomach, showed only occasional lymphoid aggregates but no evidence of MALT lymphoma. The patient is presently well, off all medication and is negative for $H$ pylori on histology and urea breath test.

\section{Discussion}

Lymphoid tissue is not present in normal gastric mucosa, but is present in the mucosa of all patients infected with $\mathrm{H}$ pylori. ${ }^{2} \mathrm{H}$ pylori is present in $92 \%$ of all patients with gastric lymphoma, ${ }^{3}$ and gastric lymphoma is significantly more common in areas where $H$ pylori is prevalent. ${ }^{4}$ This circumstantial evidence suggests an association between $H$ pylori and gastric lymphoma. Evidence for a causal relationship comes from Parsonnet, ${ }^{5}$ who demonstrated that people infected with $H$ pylori were significantly more likely to develop gastric high grade, or MALT lymphoma, and that the infection precedes development of the malignancy.

If $H$ pylori were the cause of gastric lymphoma then one would expect the tumour to regress when the organism is eradicated. There are now an increasing number of reports supporting this relationship for low grade MALT lymphoma, ${ }^{1,6}$ although eradication of $H$ pylori in cases of high grade lymphoma appears to have no effect on the progress of the disease. $^{7}$

MALT lymphomas are low-grade tumours consisting of a monoclonal proliferation of Bcells. It has been postulated that $H$ pylori antigen activates non-neoplastic $T$-cells to produce IL-2, which in turn results in the B-

1 Wotherspoon AC, Doglioni C, Diss TC, et al. Regression of primary low-grade B-cell gastric lymphoma of mucosaprimary low-grade B-cell gastric lymphoma of mucosaassociated lymphoid tissue after

2 Genta RM, Hamner HW, Graham DY. Gastric lymphoid follicles in Helicobacter pylori infection: frequency, distribution, and response to triple therapy. Hum Pathol 1993; 24: 577-83.

3 Wotherspoon AC, Ortiz Hidalgo C, Falzon MR, Issacson PG. Helicobacter pylori-associated gastritis and primary B-cell gastric lymphoma. Lancet 1991; 338: 1175-6.

4 Doglioni C, Wotherspoon AC, Moschini A, De Boni M, Issacson PG. High incidence of primary gastric lymphoma in northeastern Italy. Lancet 1992; 339: 834-5.

5 Parsonnet J, Hansen S, Rodriguez L, et al. Helicobacter pylori infection and gastric lymphoma. N Engl f Med 1994; 330: infection and

\section{Learning points}

- all gastric ulcers need to be biopsied and examined histologically

- $H$ pylori eradication therapy is an acceptable first-line treatment for low-grade gastric MALT lymphomas, irrespective of size

- this approach is not suitable for high-grade lesions

- careful long-term follow-up of these patients is mandatory as the recurrence rate amongst apparently disease-free patients is not known

cell proliferation. ${ }^{8}$ However, the observation that not all low-grade tumours respond to $H$ pylori eradication has led to the hypothesis that tumours which are initially $H$ pylori dependent become $H$ pylori independent and eventually, high-grade tumours. It is possible that these changes are mediated via translocations such as $1: 14$, trisomy 3 , or alterations in the P53 protein.

The majority of tumours reported in the literature to have regressed following treatment of $H$ pylori have been small, low volume lesions. Weber described the regression of a $10-\mathrm{cm}$ ulcer, ${ }^{9}$ but otherwise evidence for treatment of large tumours is sparse. This report also concerns a large ulcer, and hence lends support to the view that the initial treatment for these malignancies should be $H$ pylori eradication therapy. We would urge caution, however, as a proportion of these lesions will harbour high-grade malignancy or $H$ pylori independent tissue, and hence will be unaffected by antibiotic treatment. As a result, regular follow-up to ensure endoscopic and histological improvement is mandatory. In Bayerdorffer's series there were no recurrences of disease in any of the responsive patients during a follow-up period of one year. ${ }^{6}$ As yet, no long-term studies exist to assess the longterm prognosis of MALT lymphomas treated in this way.

6 Bayerdorffer E, Neubauer A, Rudolph B, et al. Regression of primary gastric lymphoma of mucosa-related lymphoid tissue after cure of Helicobacter pylori infection. Lancet 1995; 345: $1591-4$.

7 Pescatore P, Heine M, Manegold BC. Cure of gastric lymphoma with antibiotics. Gastroenterology 1995; 109: 334-

8 Hussell T, Issacson PG, Crabtree JE, Spencer J. The response of cells from low-grade-B-cell gastric lymphomas of mucosa-associated lymphoid tissue to Helicobacter pylori. Lancet 1993; 342: $571-4$

9 Weber D, Dimopoulos M, Anandu D, Pugh W, Steinbach G. Regression of gastric lymphoma of mucosa-associated lymphoid tissue with antibiotic therapy for Helicobacter pylori. Gastroenterology 1994; 107: 1835-8. 